\title{
The Assessment of Argumentation from Expert Opinion
}

\author{
Jean H. M. Wagemans
}

Published online: 26 July 2011

(C) The Author(s) 2011. This article is published with open access at Springerlink.com

\begin{abstract}
In this contribution, I will develop a comprehensive tool for the reconstruction and evaluation of argumentation from expert opinion. This is done by analyzing and then combining two dialectical accounts of this type of argumentation. Walton's account of the 'appeal to expert opinion' provides a number of useful, but fairly unsystematic suggestions for critical questions pertaining to argumentation from expert opinion. The pragma-dialectical account of 'argumentation from authority' offers a clear and systematic, but fairly general framework for the reconstruction and evaluation of this type of argumentation. The tool is developed by incorporating Walton's critical questions into a pragma-dialectical framework.
\end{abstract}

Keywords Argumentation from expert opinion - Argument scheme · Critical questions · Walton · Pragma-dialectics

\section{Introduction}

The purpose of this paper is to develop a tool for the critical assessment of argumentation from expert opinion. ${ }^{1}$ The paper is premised on the idea that the development of such a tool may greatly benefit from insights concerning the reconstruction and evaluation of argumentative discourse developed within the field of argumentation theory-especially the notion of an "argument scheme".

\footnotetext{
${ }^{1}$ I would like to thank Francisca Snoeck Henkemans, Roosmaryn Pilgram, Gábor Kutrovátz, Gábor Zemplén and two anonymous referees for their helpful comments to an earlier version of this contribution.
}

J. H. M. Wagemans (殴

University of Amsterdam, Amsterdam, The Netherlands

e-mail: J.H.M.Wagemans@uva.nl 
First, I will explain what exactly is meant by an "expert opinion" and in what argumentative situations such an opinion may play a role (Sect. 2). Next, I will scrutinize some of the extant accounts of "argumentation from expert opinion" (Sect. 3). I will then combine Walton's account of the "appeal to expert opinion" with the pragma-dialectical account of "argumentation from authority" and present a comprehensive tool for reconstructing and evaluating argumentation from expert opinion (Sect. 4).

\section{What is Argumentation from Expert Opinion?}

In order to develop a tool for the assessment of argumentation from expert opinion, some preliminary questions should be answered. How is the term "expert" to be defined from the perspective of argumentation theory? In what argumentative situations do "expert opinions" play a role? And how is "argumentation from expert opinion" to be understood?

According to a well established tradition, an expert is "someone who is epistemically responsible for a particular domain of knowledge" (Huenemann 2004, p. 250, original italics). This characterization implies that for a person to be rightly called an expert, the person should not only know something simpliciter, but he should also be able to give an account of what he knows. Moreover, it implies that in giving such an account, the alleged expert should not refer to people he puts intellectual trust in. It is assumed that the ability of giving a proper account of the knowledge involved draws on the fact that the expert does not know something through intellectual trust in others, but knows something "for himself". 2

From the perspective of argumentation theory, this "deontic" characterization of an expert is problematic in several respects. First, the requirement that someone is able to give an account of what he knows does not exclusively apply to experts, but to all arguers that have put forward a standpoint. One of the so-called 'preparatory conditions' of the speech act of putting forward a standpoint is that the speaker believes that he is able to justify that standpoint with the help of arguments. ${ }^{3}$ Consequently, everyone who has put forward a standpoint is obliged to defend it upon request: "Discussants who advance a standpoint may not refuse to defend this standpoint when requested to do so" (van Eemeren and Grootendorst 2004, p. 191).

Second, the requirement that an expert should know something for himself rather than through intellectual trust in others may is difficult to assess. It is not easy to identify the criteria that enable the assessor to decide in every given case when

\footnotetext{
${ }^{2}$ See Huenemann (2004), who makes clear that this characterization of an expert draws on "the fundamental distinction between knowing $X$ through intellectual trust in others and knowing $X$ for oneself" (p. 251, original italics). In explaining what is meant by the latter notion, Huenemann refers to Plato's Meno 97e-98a: "For true opinions, as long as they remain, are a fine thing and all they do is good, but they are not willing to remain long, and they escape from a man's mind, so that they are not worth much until one ties them down by (giving) an account of the reason why" (translation Cooper (Ed.) (1994)). According to Huenemann, Plato suggests that knowing $X$ for oneself implies among other things that "one would continue to know X even if one were to abandon all intellectual trust in others" (2004, p. 251).

${ }^{3}$ See Houtlosser (2001, p. 32).
} 
exactly someone knows something for himself. Should the person involved have acquired the knowledge without the help of others? Should he show that his basic reasoning capacities function in an autonomous way ${ }^{4}$ And even if such criteria could be articulated in a satisfactory way, it is difficult to apply them in practice. How could it be checked whether someone has acquired the knowledge involved without the help of others? Or that someone's reasoning capacities function in an autonomous way?

For evaluative purposes, instead of characterizing an expert in terms of epistemic responsibilities, it is more appropriate to do so in terms of epistemic qualities. In this case, experts may be characterized as "people who have, or who are attributed by others, an outstanding knowledge and understanding of a certain subject or field" (Kutrovátz 2011, p. 2). In order to develop a tool for the assessment of argumentation from expert opinion, it is helpful to reformulate this characterization by taking the argumentative context into account. There are at least two different argumentative situations in which an opinion of an "expert" characterized as above may play a role.

First, it might be the case that an expert has put forward an opinion without using or mentioning the fact that he is an expert as an argument in favor of the truth or acceptability of that opinion. In this situation, the fact that the arguer is an expert is irrelevant for the assessment of the opinion. Of course, the addressee might be more inclined to accept what the arguer has asserted than in the case that the opinion is asserted by someone who is not an expert on the matter. But that is a psychological issue, rather than an argumentation theoretical one.

Second, it might be the case that someone is defending the standpoint that a certain opinion is true or acceptable by referring to himself as an expert or by mentioning that an expert — other than the arguer — has asserted the same opinion. ${ }^{5}$ In this situation, the claim that the opinion involved is an "expert opinion" functions as an argument for the truth or acceptability of that opinion. The arguer qualifies a certain opinion as stemming from an intellectually trustworthy source and, more importantly, explicitly uses this qualification as an argument in favor of it.

Summarizing, an "expert" may be characterized as "someone of whom the arguer believes the addressee to put a certain intellectual trust in". Further, "argumentation from expert opinion" may be characterized as "argumentation that renders an opinion (more) acceptable by claiming that the opinion is asserted by an expert." Finally, in technical terms, with $\mathrm{O}$ denoting an opinion and $\mathrm{E}$ denoting an expert, the standpoint involved has as its propositional content " $\mathrm{O}$ is true or acceptable" and is supported by an argument that has as its propositional content " $\mathrm{O}$ is asserted by $\mathrm{E}$ ".

\section{A Critical Analysis of Extant Accounts}

Within the field of argumentation theory, several authors have provided an account of what is called "argumentation from authority". Some authors prefer the term

\footnotetext{
${ }^{4}$ Both possibilities are scrutinized in Hueneman (2004, pp. 251-252).

5 See also Pilgram (2011, p. 5), who labels these possibilities as "argument by authority" and "argument from authority" respectively.
} 
argumentum ad verecundiam, following on Locke's (1690, c. XVII, 19) description of the type of argument at issue:

The first [of four sorts of arguments that men, in their reasonings with others, do ordinarily make use of to prevail on their assent; or at least so to awe them as to silence their opposition] is, to allege the opinions of men, whose parts, learning, eminency, power, or some other cause has gained a name, and settled their reputation in the common esteem with some kind of authority. When men are established in any kind of dignity, it is thought a breach of modesty for others to derogate any way from it, and question the authority of men who are in possession of it. This is apt to be censured, as carrying with it too much pride, when a man does not readily yield to the determination of approved authors, which is wont to be received with respect and submission by others: and it is looked upon as insolence, for a man to set up and adhere to his own opinion against the current stream of antiquity; or to put it in the balance against that of some learned doctor, or otherwise approved writer. Whoever backs his tenets with such authorities, thinks he ought thereby to carry the cause, and is ready to style it impudence in any one who shall stand out against them. This I think may be called argumentum ad verecundiam.

Instead of using the term argumentum ad verecundiam as a general label and distinguishing between fallacious and non-fallacious ways of using such an argument, I will follow the pragma-dialectical terminology in which an argumentum ad verecundiam is the name of a fallacy, that is, a label exclusively used for fallacious argumentation from authority. ${ }^{6}$

In their analysis of "argumentation from authority," some authors do not specify which type of authority they mean. Others prefer a terminology in which "authority" always denotes "expert":

[By an authority] we do not mean a person who is in a position of authority (priest, politician, teacher, boss) and who is therefore able to command others to act in certain ways, or to do certain things. We mean someone whose expertise in a particular area makes his assertions reliable-more likely to be true than false. (Johnson and Blair 1983, p. 144 as cited by Walton 1997, p. 85).

Taking into account that there are many types of authority to which arguers may appeal in their argumentation, I prefer to conceive "argumentation from expert opinion" as a species of "argumentation from authority". On the basis of a research into several definitions of authority, Walton (1997, p. 78) distinguishes between an appeal to de facto (cognitive, epistemic) authority-an appeal to expertise or expert opinion-and de iure (administrative, deontic) authority - an appeal to a right to exercise command. ${ }^{7}$ In line with this distinction, I propose to make a distinction between "argumentation from invested opinion", and "argumentation from expert

\footnotetext{
${ }^{6}$ See Van Eemeren and Houtlosser (2003, p. 291, n. 10).

7 On different types of appeals to authority see also Goodwin (1998), who distinguishes between appeals that are based on a command, appeals that are based on expertise, and appeals that are based on dignity.
} 


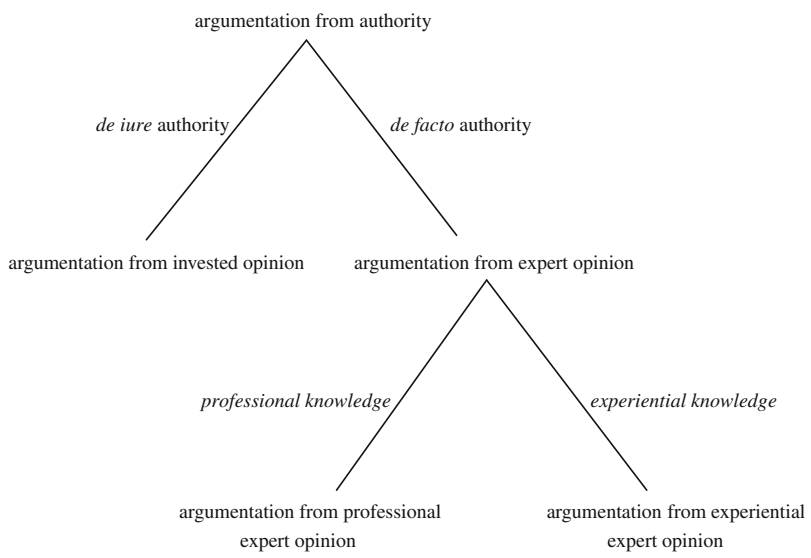

Fig. 1 Different types of argumentation from authority

opinion". Since experts may have acquired their knowledge in different ways, I further propose to make a distinction between "argumentation from professional expert opinion" and "argumentation from experiential expert opinion" (see Fig. 1).

As to the assessment of argumentation from expert opinion, some authors evaluating the reasonableness of argumentation from an "epistemic" perspective take such an argument to be fallacious by definition: "P (the probandum, or proposition to be proved) should be proved by adequate evidence, but the fact that $\mathrm{X}$ says it is true is not evidence for its truth. The citing of authority is an evasion of the law of rationality" (Ruby 1950, p. 128, as quoted by Walton 1997, p. 66). ${ }^{8}$ According to other authors, the reasonableness of argumentation from expert opinion depends on certain contextual factors. Textbook examples of fallacious argumentation from expert opinion often consist of argumentation in which the alleged "expert" is not in fact an expert or is an expert on something different than the subject matter at issue.

Walton (1997) provides an inventory of the conditions various authors have proposed for deciding whether or not a certain appeal to authority is fallacious. These conditions may concern the expert (e.g. his competence, credibility, sincerity, prestige, degree of recognition), the opinion (e.g. accuracy and verifiability of the representation, evidence), or the relation between the expert opinion and the field of expertise (e.g. inclusion, derivability, agreement with other expert opinions). Partly based on this extensive research, Walton (2006, p. 750) proposes the following argument scheme and associated critical questions for the appeal to expert opinion:

\footnotetext{
${ }^{8}$ The same position is defended by Hyslop, be it that he first makes a distinction between argumentum ad rem and argumentum ad personam and then defines the argumentum ad verecundiam as a species of the argumentum ad personam that appeals to an authority accepted by the opponent: "The argumentum ad verecundiam is an appeal to authority, or body of accepted doctrines. It is valid for producing conviction when the authority is accepted by the persons to whom the appeal is addressed, but it is not ad rem proof [...]" (1899, pp. 175-176, cited by Walton 1997, pp. 68-69).
} 


\section{Argument Scheme}

Source Premise: Source E is an expert in subject domain S containing proposition A.

Assertion Premise: E asserts that proposition A (in domain S) is true (false).

Warrant Premise: If source $\mathrm{E}$ is an expert in subject domain $\mathrm{S}$ containing proposition $\mathrm{A}$, and $\mathrm{E}$ asserts that proposition $\mathrm{A}$ (in domain $\mathrm{S}$ ) is true (false), then $\mathrm{A}$ may plausibly be taken to be true (false).

Conclusion: A may plausibly be taken to be true (false).

\section{Basic Critical Questions}

1. Expertise Question: How credible is E as an expert source?

2. Field Question: Is $\mathrm{E}$ an expert in the field that $\mathrm{A}$ is in?

3. Opinion Question: What did E assert that implies A?

4. Trustworthiness Question: Is E personally reliable as a source?

5. Consistency Question: Is A consistent with what other experts assert?

6. Backup Evidence Question: Is E's assertion based on evidence?

Since Walton's proposal is the result of an extensive research into many different accounts of argumentation from expert opinion, one may assume that many experts in the field of argumentation theory agree as to the relevance and importance of the elements of the scheme and the critical questions mentioned above. However, from a systematic point of view, some criticisms can be made.

First, it is not always clear in what way, if at all, the critical questions relate to the scheme. Evidently, the Trustworthiness Question (4), the Consistency Question (5) and the Backup Evidence Question (6) relate to the Warrant Premise. However, it is unclear to which parts of the Source Premise the Expertise Question (1) and the Field Question (2) exactly relate. Moreover, the Opinion Question (3) seems to relate to the Source Premise and the Assertion Premise at the same time.

Second, not all of the critical questions are suitable for evaluating the quality of the argumentation at issue in a clear and unambiguous way. It is to be assumed that a positive answer to Questions 2, 4, 5, and 6 results in a positive assessment of the argumentation. But unlike these questions, which are closed and binary in nature, the Expertise Question (1) requires a gradual statement as an answer and the Opinion Question (3) requires a complete proposition as an answer. In these cases, it remains unclear when exactly the answer is satisfactory. Moreover, the Backup Evidence Question (6) does not seem to pertain to the quality of the evidence, but only to its existence.

All in all, Walton's proposal contains elements that seem relevant and important for the development of a tool for the assessment of argumentation from expert opinion. However, it should be taken into account that the critical questions proposed only partly relate to the argument scheme presented and that not all of them are equally suitable for evaluative purposes.

A more systematic approach to the relation between argument schemes and their associated critical questions is that of the pragma-dialectical theory of argumentation. Within this theory, critical questions always pertain to the justificatory force 
of the explicit argument. Argumentation from expert opinion is conceived as argumentation from authority, which is a subtype of symptomatic argumentation. An example of symptomatic argumentation is the following:

1 Daniel $(\mathrm{X})$ is concerned about the costs $(\mathrm{Y})$.

1.1 Daniel (X) is an American (Z).

1.1' Being an American (Z) goes characteristically together with being concerned about the costs $(\mathrm{Y})$.

The associated critical question pertains to the justificatory force of argument 1.1 (that is expressed in argument $1.1^{\prime}$ ): "Does being an American indeed go characteristically together with being concerned about the costs?" 9

Having scrutinized the pragma-dialectical account of argument schemes, Hitchcock and Wagemans (2011) show that there is a principled division of potentially correct schemes into "predicate-transfer" schemes and "referenttransfer" schemes. In terms of their proposed revision of the pragma-dialectical typology, argumentation employing a predicate-transfer scheme is called "sign argumentation" and argumentation employing a referent-transfer scheme is called "similarity argumentation". They take argumentation from authority to be a subtype of sign argumentation and suggest the following formulation of the unexpressed premise: "being uttered by authority $\mathrm{A}(=\mathrm{Z})$ is generally an indication of being true or acceptable (=Y)" (p. 199). ${ }^{10}$

In the case of argumentation from expert opinion, the scheme and the associated critical question should be further specified. I propose to do so by substituting "being asserted by expert E" for Z, "Opinion $\mathrm{O}$ " for $\mathrm{X}$, and "being true or acceptable" for $\mathrm{Y}$. This results in the following scheme for argumentation from expert opinion:

1 Opinion $\mathrm{O}(\mathrm{X})$ is true or acceptable $(\mathrm{Y})$.

1.1 Opinion $\mathrm{O}(\mathrm{X})$ is asserted by expert $\mathrm{E}(\mathrm{Z})$.

$1.1^{\prime}$ Being asserted by expert $\mathrm{E}(=\mathrm{Z})$ is an indication of being true or acceptable $(=\mathrm{Y})$.

The associated general critical question may then be formulated as follows: "Is being asserted by expert E indeed an indication of being true or acceptable?"

In comparison to Walton's account of argumentation from expert opinion, the pragma-dialectical account is more systematic, but less specific. There is only one critical question, and there is no specification of the arguments the arguer may provide in anticipation of doubt or criticisms with regard to that question. In the next section, I will combine the two dialectical accounts into a comprehensive tool for assessing argumentation from expert opinion.

\footnotetext{
${ }^{9}$ For a summary of the pragma-dialectical account of argument schemes including references to the relevant pragma-dialectical literature, see Hitchcock and Wagemans (2011, pp. 185-189).

10 This formulation is in accordance with the suggestion by Van Eemeren and Grootendorst (1992, p. 163) that "one of the critical questions that needs to be answered is whether [the] authority really guarantees [the] acceptability [of the proposition involved]."
} 


\section{A Comprehensive Tool for Assessing Argumentation from Expert Opinion}

In actual argumentative discourse, it is often the case that elements that are relevant for the evaluation remain implicit. Within the pragma-dialectical approach to argumentation, some of these implicit elements are made more explicit by analyzing the commitments of the arguer. When someone, for instance, has put forward a standpoint and an argument, he is not only committed to the acceptability of the propositional content of the standpoint and the argument, but also to the justificatory force of the argument. By expressing the latter commitment in the form of a statement, the analyst has provided a theoretically motivated reconstruction of the unexpressed premise in the form of what can be called an 'acceptability transfer principle' or ATP: "Accepting the argument renders the standpoint acceptable." Abbreviating the standpoint as STP and the argument as ARG, a fully explicit reconstruction then consists of the following elements:

1 STP

$1.1 \quad$ ARG

$1.1^{\prime} \quad$ ATP $(1.1 \rightarrow 1)$

Further, according to the pragma-dialectical rules for a critical discussion, the addressee of the argumentation is entitled to doubt or criticize the acceptability and/or the justificatory force of the argument or-in terms of the reconstruction above-the explicit argument (1.1) and/or the acceptability transfer principle $\left(1.1^{\prime}\right)$. This rule may be used in order to reconstruct the attempts of the arguer to meet the real or anticipated doubt or criticism of the addressee by putting forward subordinative argumentation. Such an attempt can either be reconstructed as an argument in support of the original explicit argument (1.1.1) or as an argument in support of the acceptability transfer principle $\left(1.1^{\prime} .1\right)$. Since both arguments come with new acceptability transfer principles, a fully explicit reconstruction consists of the following elements:

1 STP

1.1 ARG

1.1.1 ARG

1.1.1' $\operatorname{ATP}(1.1 .1 \rightarrow 1.1)$

$1.1^{\prime} \quad \operatorname{ATP}(1.1 \rightarrow 1)$

\section{$1.1^{\prime} .1 \quad$ ARG \\ $1.1^{\prime} .1^{\prime} \quad \operatorname{ATP}\left(1.1^{\prime} 1 \rightarrow 1.1^{\prime}\right)$}

Of course, these subordinative arguments may again be supported by other arguments, thereby creating a sub-subordinative level of argumentation. ${ }^{12}$

\footnotetext{
${ }^{11}$ See Wagemans $(2008,2011)$. The ATP differs from other formulations of the "unexpressed premise" (like Toulmin's "warrant", the pragma-dialectical "pragmatic optimum", etc.) in that it is a general expression of the speaker's commitment with regard to the justificatory force of any explicit argument put forward by him. Cf. Toulmin (2003, Chap. 3); van Eemeren and Grootendorst (1992, Chap. 6); Govier (1987, Chap. 5); Garssen (2001).

${ }^{12}$ For a more elaborated account of this argumentation structure, see Wagemans $(2008,2011)$.
} 
I will now use this general framework of the structure of argumentation in order to combine Walton's account of argumentation from expert opinion with the pragma-dialectical account of this type of argumentation. Keeping in mind that arguments can be interpreted as answers to critical questions and that they may provide further support for the propositional content as well as the justificatory force of any argument that has already been put forward, the combination results in the following scheme for argumentation from expert opinion:

$1 \mathrm{O}$ is true or acceptable.

$1.1 \mathrm{O}$ is asserted by expert $\mathrm{E}$.

1.1.1a $\mathrm{E}$ is an expert in the relevant field $\mathrm{F}$.

1.1.1b Source $\mathrm{S}$ proves that $\mathrm{O}$ is asserted by $\mathrm{E}$.

1.1' Accepting that $\mathrm{O}$ is asserted by $\mathrm{E}$ renders acceptable that $\mathrm{O}$ is true or acceptable.

$1.1^{\prime} .1 \mathrm{a} \quad \mathrm{E}$ is personally reliable.

$1.1^{\prime} .1 \mathrm{~b} \quad \mathrm{E}$ is able to provide further evidence for $\mathrm{O}$.

$1.1^{\prime} .1 \mathrm{c} \quad \mathrm{O}$ is consistent with what other (types of) experts on $\mathrm{F}$ assert.

The scheme clearly indicates how the various arguments relate to the standpoint and the other arguments put forward in this context. Arguments 1.1.1a and 1.1.1b are to be interpreted as evidence supporting the propositional content of argument 1.1. ${ }^{13}$ Argument 1.1.1a combines the Expertise Question and the Field Question and addresses the antagonist's possible doubts regarding the credibility of $\mathrm{E}$ as an expert. Argument 1.1.1b is inspired on the Opinion Question and addresses the antagonist's possible doubt regarding the accuracy of the protagonist's representation of $\mathrm{O}$ (or regarding $\mathrm{E}$ asserting $\mathrm{O}$ at all). The importance of addressing this type of doubt is also stressed by Kerfert in an earlier version of his contribution to this issue: "when we accept such an appeal [to expert opinion], we do not rely on the epistemic authority of the putative expert alone-we also rely on the speaker's functioning as a successful conduit for the expert's opinions."

Arguments $1.1^{\prime} .1 \mathrm{a}, 1.1^{\prime} .1 \mathrm{~b}$, and $1.1^{\prime} .1 \mathrm{c}$ are to be interpreted as evidence supporting the specific acceptability transfer principle of argumentation from expert opinion or, in other words, the justificatory force of 1.1 as it is expressed in $1.1^{\prime}$. The arguments are inspired on the Trustworthiness Question, Backup Evidence Question, and Consistency Question respectively and they address the antagonist's possible doubt regarding these issues. I do not claim that this is an exhaustive list of all the ways in which the antagonist may doubt the transfer of acceptability. Depending on the issue at hand, it may be appropriate to add other arguments to this part of the scheme. This should be done under the proviso that the arguments serve the purpose of showing that accepting that $\mathrm{O}$ is asserted by $\mathrm{E}$ renders acceptable that $\mathrm{O}$ is true or acceptable.

\footnotetext{
13 Since argument 1.1 is only to be deemed true or acceptable when argument 1.1.1a and 1.1.1b are both true or acceptable, the argumentation supporting 1.1 is coordinative (and not multiple). See for example Van Eemeren and Grootendorst (2004, p. 4).
} 
As Goodwin rightly observes in an earlier version of her contribution to this issue, all criteria for judging argumentation from expert opinion are 'external' in the sense that there is no possibility of verifying directly what the expert actually claims to know. The truth or acceptability of opinion $\mathrm{O}$ can only be critically tested in an indirect way, namely by asking questions pertaining to the propositional content and the justificatory force of the statement "O is asserted by E". As to the evaluation of such argumentation from expert opinion, I suggest that the pragma-dialectical argument scheme rule applies. ${ }^{14}$ Only in cases where this rule is violated, the protagonist may be accused of having committed the fallacy of the argumentum ad verecundiam.

The rule may be violated in two ways: (1) using the scheme may be inappropriate; (2) the scheme may be incorrectly applied. Whether or not using the scheme is inappropriate, is to be decided by the discussants. They should agree on the formal starting point that it is allowed to defend a standpoint by referring to an expert opinion. Whether or not the scheme has been applied correctly, depends on whether the protagonist is able to answer the associated critical question in a satisfactory way. As indicated in the scheme, several arguments may serve this purpose, and it is up to the antagonist whether or not the arguments are acceptable and whether or not they provide sufficient support. The discussants may have agreed on formal starting points regarding these issues as well. ${ }^{15}$

Open Access This article is distributed under the terms of the Creative Commons Attribution Noncommercial License which permits any noncommercial use, distribution, and reproduction in any medium, provided the original author(s) and source are credited.

\section{References}

Garssen, B.J. 2001. Argument schemes. In Crucial concepts in argumentation theory, ed. F.H. van Eemeren, 81-99. Amsterdam: Amsterdam University Press.

Goodwin, J. 1998. Forms of authority and the real ad verecundiam. Argumentation 12: 267-280.

Govier, T. 1987. Problems in argument analysis and evaluation. Berlin: Foris/Mouton de Gruyter.

Hitchcock, D., and J.H.M. Wagemans. 2011. The pragma-dialectical account of argument schemes. In Keeping in touch with pragma-dialectics, ed. B.J. Garssen, and A.F. Snoeck Henkemans, 185-205. Amsterdam: Benjamins.

Houtlosser, P. 2001. Points of view. In Crucial concepts in argumentation theory, ed. van Eemeren F.H., 27-50. Amsterdam: Amsterdam University Press.

Huenemann, Ch. 2004. Why not to trust other philosophers. American Philosophical Quarterly 41(3): 249-258.

Kutrovátz, G. 2011. Expert authority and ad verecundiam arguments. In Proceedings of the seventh conference of the international society for the study of argumentation eds. van Eemeren, F.H., B.J. Garssen, D. Godden, and G. Mitchell, 1050-1061. Amsterdam: Rozenberg/Sic Sat. CD-ROM.

Locke, J. 1961 (1690). An essay concerning human understanding. 2 Vol. ed. John W. Yolton. London: Dent.

\footnotetext{
${ }^{14}$ See Van Eemeren and Grootendorst (1992, pp. 158-168); Garssen (2001, p. 91); Hitchcock and Wagemans (2011, pp. 189-190).

15 See also Van Eemeren (2010, p. 205), who remarks with respect to argumentation from authority that if "the parties in the discussion have agreed beforehand that an appeal to authority is legitimate" and "the agreement allows an appeal to precisely the authority that is actually (correctly) appealed to [...] no argumentum ad verecundiam has been committed."
} 
Pilgram, R. 2011. A doctor's argumentation by authority as a strategic manoeuvre. In Proceedings of the seventh conference of the international society for the study of argumentation eds. van Eemeren, F.H., B.J. Garssen, D. Godden, and G. Mitchell, 1527-1537. Amsterdam: Rozenberg/Sic Sat. CDROM.

Toulmin, S.E. 2003. (1958). The uses of argument. Updated edition. Cambridge: Cambridge University Press.

van Eemeren, F.H., and R. Grootendorst. 1992. Argumentation, communication, and fallacies: A pragmadialectical perspective. Hillsdale, NJ: Lawrence Erlbaum Associates.

van Eemeren, F.H., and P. Houtlosser. 2003. Fallacies as derailments of strategic maneuvering: The argumentum ad verecundiam, a case in point. In Proceedings of the fifth conference of the international society for the study of argumentation, eds. van Eemeren, F.H., J.A. Blair, Ch. A. Willard, and A.F. Snoeck Henkemans, 289-292. Amsterdam: Sic Sat.

van Eemeren, F.H., and R. Grootendorst. 2004. A systematic theory of argumentation: The pragmadialectical approach. Cambridge: Cambridge University Press.

van Eemeren, F.H. 2010. Strategic maneuvering in argumentative discourse: Extending the pragmadialectical theory of argumentation. Amsterdam/Philadelphia: Benjamins.

Wagemans, J.H.M. 2008. De relatie tussen argumentatieschema's en topen [The relation between argumentation schemes and topoi]. Paper presented at the VIOT 2008 conference at VU University, Amsterdam.

Wagemans, J.H.M. 2011. Argument schemes, topoi, and laws of logic. In Proceedings of the seventh conference of the international society for the study of argumentation eds. van Eemeren F.H., B.J. Garssen, D. Godden, and G. Mitchell, 1934-1939. Amsterdam: Rozenberg/Sic Sat. CD-ROM.

Walton, D.N. 1997. Appeal to expert opinion: Arguments from authority. University Park, PA: Penn State University Press.

Walton, D.N. 2006. Examination dialogue: A framework for critically questioning an expert opinion. Journal of Pragmatics 38: 745-777. 